•研究报告・

\title{
佤族传统文化在生物多样性保护中的作用
}

\section{邵桦(1) ${ }^{1,2}$ ，杨京䖌(11,2*，薛达元 (1) 1 2*}

1. 中央民族大学生命与环境科学学院，北京 100081; 2. 国家民委民族地区生态环境重点实验室，中央民族大学，北京 100081

摘要: 生物多样性与文化多样性相辅相成, 传统文化对生物多样性的保护作用已经得到广泛认可。低族在长期利用和管理当 地生物资源的过程中形成了丰富的民族文化, 研究佤族传统文化对生物多样性的保护作用对当地生物多样性保护和可持续 发展具有重要意义。本研究以仾族聚居人口最多的西盟低族自治县与沧源低族自治县作为研究区域, 采用生态学和民族学方 法调查了仾族利用的野生植物资源及相关传统文化。结果表明: 低族传统使用的野生植物十分丰富, 是当地低族形成传统饮 食、医药、服饰、建筑文化的物质基础。基于自然崇拜形成的生态观、习惯法和节庆习俗可促进当地生物多样性保护与生物 资源可持续利用。地方政府在传统文化和传统知识保护方面做出了积极努力，非物质文化遗产项目已经应用于扶贫和乡村振 兴的产业发展; 市场化和城市化发展、生活方式改变、生物资源减少、保护意识薄弱、外来文化侵蚀等是文化多样性丧失的 主要因素; 地方社区将特色生物资源转化为生态产品的能力不足, 制约了生物资源的可持续利用。因此, 亟需健全保护传统 知识和传承民族文化的政策和制度, 建立传统知识数据库, 加强宣传教育、科学研究和人才培养, 充分发挥少数民族优秀传 统文化在生物多样性保护与生物资源可持续利用中的积极作用。

关键词: 传统文化; 生物多样性; 传统知识; 㑑族; 云南; 中国

邵华，杨京彪，薛达元 (2021) 低族传统文化在生物多样性保护中的作用. 生物多样性, 29, 1120-1127. doi: 10.17520/biods.2020480.

Shao H, Yang JB, Xue DY (2021) Applications of Wa traditional culture on biodiversity conservation. Biodiversity Science, 29, 1120-1127. doi: 10.17520/biods.2020480.

\section{Applications of Wa traditional culture in biodiversity conservation}

Hua Shao ${ }^{\left(\mathbb{1}_{1,2}\right.}$, Jingbiao Yang ${ }^{\mathbb{D}_{1,2^{*}}}$, Dayuan Xue ${ }^{\mathbb{D}_{1,2^{*}}}$

1 College of Life and Environmental Sciences, Minzu University of China, Beijing 100081

2 Key Laboratory of Ecology and Environment in Minority Areas, Minzu University of China, National Ethnic Affairs Commission, Beijing 100081

\section{ABSTRACT}

Aims: There is an emerging recognition that cultural diversity and biodiversity are inherently linked. Wa people have formed a rich culture in the long process of utilization and management of biological resources from local areas. This study reports the wild plants traditionally used by Wa people and related traditional culture. It is of great significance to understand the interaction between Wa traditional culture and biodiversity for sustainable development of the community.

Methods: We investigated the wild plants traditionally used by Wa people and their culture in Cangyuan and Ximeng autonomous counties by a semi-structured interview method to gather the plant inventory and culture information.

Results: The wild plants traditionally used by Wa people are abundant, and are the basis for their traditional diet, medicine, clothing, and architectural culture. The ecological view, customary law, and customs of Wa people based on nature worship are constantly promoting the conservation and sustainable utilization of biodiversity in the local areas. Local governments have made efforts to protect the traditional culture and knowledge. For example, intangible cultural heritage projects have been applied to facilitate industrial development for poverty alleviation and rural revitalization. The factors of cultural diversity loss include marketization and urbanization, lifestyle changes, weak protection consciousness, and invasion of foreign culture. Local communities' incompetence to transform characteristic biological resources into ecological products also restricts the sustainable utilization of bioresources.

收稿日期: 2020-12-25; 接受日期: 2021-04-09

基金项目: 生态环境部生物多样性调查、观测和评估项目(2019-2023年)

* 通讯作者 Author for correspondence. E-mail: xuedayuan@hotmail.com; yangjingbiao@muc.edu.cn 
Recommendations: Our recommendations include improving policies and regulations for traditional knowledge and culture, establishing databases of traditional knowledge, strengthening publicity activities and education to enhance the awareness of protection and inheritance, facilitating scientific knowledge research and professional experts training. Overall, promoting cultural diversity could be a promising approach for biodiversity conservation and sustainable use of bioresources in the ethnic minority areas.

Key words: traditional culture; biodiversity conservation; Wa people; Yunnan Province; China

生物多样性保护已经成为当今国际社会的热 点议题。1993年生效的《生物多样性公约》不仅明 确了生物多样性的定义, 也要求缔约方在保护生物 多样性的同时保护与之相关的文化和传统知识(薛 达元和郭泺, 2009)。2006年通过的《保护和促进文 化表现形式多样性公约》进一步指出文化多样性和 生物多样性与可持续发展之间的关系。联合国教科 文组织使用生物文化多样性 (biocultural diversity) 指生物多样性和文化多样性之间的复杂联系, 包括 生物多样性、文化多样性和两者之间的复杂联系和 相互作用(Loh \& Harmon, 2005; Persic \& Martin, 2008; Cocks \& Wiersum, 2014)。

生物多样性与文化多样性之间相互联系, 也面 临共同的丧失威胁(Pretty et al, 2009)。在特定文化 背景下, 人类在开发利用生物资源的长期实践过程 中形成了丰富的文化多样性(图1) (Hill et al, 2011; Plieninger et al, 2018)。传统文化对生物多样性保护 发挥了积极作用, 例如神林生境对生物多样性的保 护(杨立新等, 2019; Pradhan \& Ormsby, 2020)。我国 民族传统文化已经证明对生物多样性保护具有重
要作用(龙春林和裴盛基，2003; 刀志灵等，2003)。 各个民族在生产生活实践过程中发展了丰富的传 统文化，少数民族通过信仰、传统习惯法、民风民 俗、乡规民约等形成了对生物多样性的保护机制(龙 春林等, 1999; 许再富, 2015; 曹宁和薛达元, 2019)。 传统知识是土著和地方社区对生物多样性保护和 可持续利用相关的传统生活方式的知识、创新和做 法(薛达元和郭泺, 2009), 被视为生物多样性与文化 多样性的共同交集，对于保护生物多样性有着重要 作用(毛舒欣等, 2017)。与生物多样性有关的传统知 识具有深刻的文化内涵, 例如在长期选育、利用和 保存当地稻作资源的实践中形成了独特的稻作文 化(冯建孟等, 2010; 王艳杰等, 2015)。然而, 由于社 会变迁和发展压力, 在不同国家的地方社区都出现 了传统知识和文化伴随生物多样性的消失而面临 丧失威胁 (Singh et al, 2010)。越来越多的研究认为 传统文化与传统知识是未来应对生物多样性丧失 的有利工具(Ens et al, 2015; Frainer et al, 2020)。

仾族是云南的特有民族, 我国现有低族人口 42.9 万(第六次人口普查数据), 云南省的恆族人口

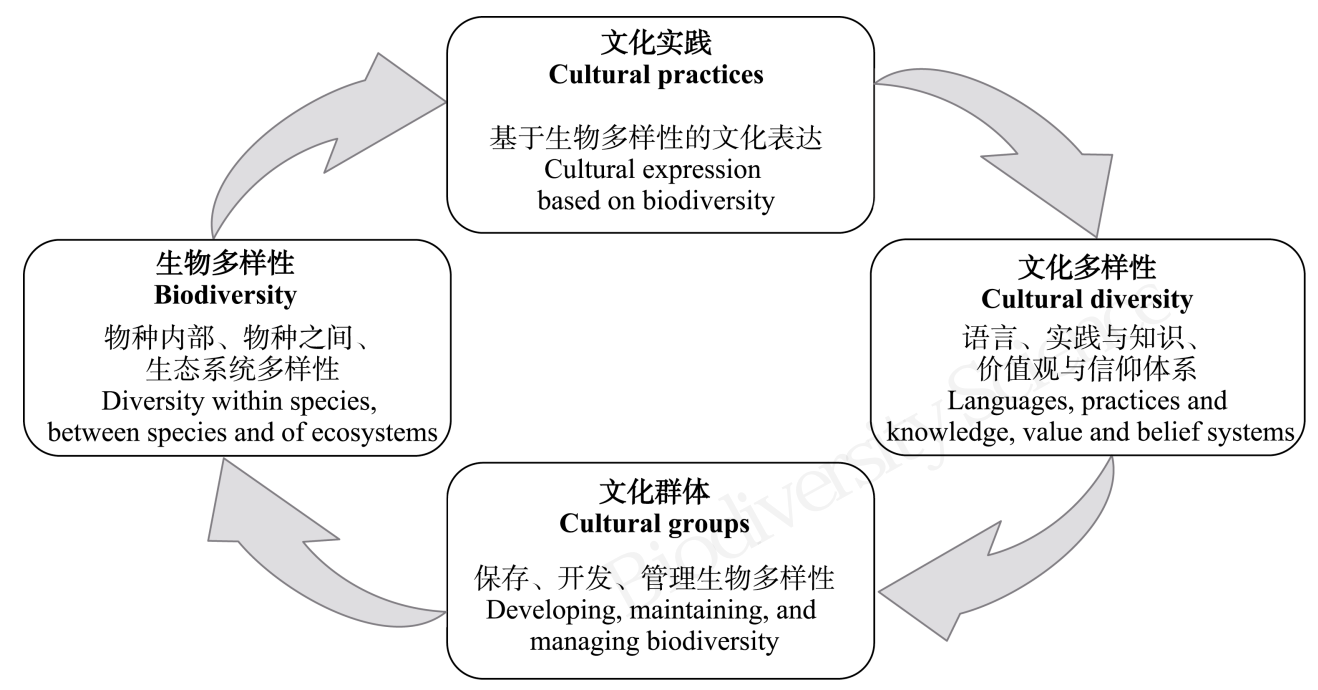

图1 文化多样性与生物多样性的关系(修改自Persic \& Martin, 2008)

Fig. 1 Relations between cultural diversity and biodiversity (adopted from Persic \& Martin, 2008) 
占全国㑑族人口的 $98.8 \%$ 。俩族主要聚居地位于 $22^{\circ} 25^{\prime}-22^{\circ} 57^{\prime} \mathrm{N}, 99^{\circ} 18^{\prime}-99^{\circ} 43^{\prime} \mathrm{E}$, 分布在云南省西 南部澜沧江和怒江之间、怒山山脉南段的阿仾山 区。该区域属于亚热带气候, 平均海拔 $1,300 \mathrm{~m}$ 左右, 有干季和雨季之分, 雨量充沛。优越的自然环境条 件造就了该区域动植物种类繁多、生物多样性丰富 的特点, 为㑑族形成生物多样性相关的实践知识和 民族文化提供了物质基础。低族历史上发展传统农 业, 采集和狩猎也是重要的生产方式, 因此在长期 的生活实践中掌握了对当地动植物资源可持续利 用的传统知识, 通过传统信仰、习惯法和节庆祭祀 的文化形式表现人与自然和谐的理念, 形成了独特 的佤族生态文化观(罗之基, 1995; 孟建林, 2010)。

沧源恆族自治县和西盟仾族自治县境内低族 人口占比最大, 是典型的佤族人口聚居地和低族文 化研究的热点地区。作者于2017-2019年进行了实 地考察, 研究地点包括: 沧源佤族自治县的糯良乡 的贺岭村与怕拍村, 预角乡的翁丁村, 班老乡的芒 黑村, 西盟仾族自治县中课镇的中课村、班等村与 窝笼村, 岳宋乡的岳宋村永老寨、班帅村翁斯代寨 与曼亨村, 预卡镇的马散村以及预梭镇的秧洛村, 对当地生物资源和俪族传统文化进行调查。主要采 用半结构式访谈(semi-structured interview)方法, 共 调查 13 个㑑族聚居村寨的 75 人(附录 1 )。调查记录恆 族利用的生物资源, 并且了解相关的民族文化和利 用生物资源的传统文化知识。本研究以㑑族聚居人 口最多的西盟仾族自治县与沧源仾族自治县作为 研究区域, 探讨生物多样性与低族文化多样性的相 互关系, 从不同角度讨论仾族传统文化对生物多样 性保护做出的贡献, 针对传统文化的发展现状和受 威胁因素, 提出保护传统文化以促进当地生物多样 性保护与生物资源可持续利用的建议。

\section{1 仾族利用生物资源的传统文化}

㑑族对当地植物的管理与利用形成了丰富的 生产生活实践经验以及与周围自然环境和生物资 源密切相关的传统文化, 同时掌握了可持续利用和 管理的野生植物的传统知识。根据用途分为食用植 物(包括野菜、野果、竹笋等)、具有医疗和保健用 途的药用植物、用于建筑的纤维植物和竹类植物, 以及用于织锦的纤维植物和染料植物等。

\section{1 低族利用野生食用植物的饮食文化}

㑑族人口聚集的地区多为山地, 森林覆盖率高, 植物资源尤其丰富, 野生可食用植物资源多样。经 调查仾族人民日常利用的野生蔬菜资源有 31 科45 属50种(邵桦和薛达元, 2017), 反映出俪族地区植物 多样性丰富, 并且仍然维持了采集野生植物的生活 方式和饮食文化。

仾族的饮食文化促进了仾族人对野生食用植 物的利用, 人们逐渐掌握了对村寨周围野生食用植 物采集和驯化的传统知识。采摘嫩茎、嫩叶的野生 蔬菜如野茼蒿(Crassocephalum crepidioides)、水芹 (Oenanthe javanica)、水葓(Ceratopteris thalictroides)、 刺五加 (Eleutherococcus senticosus) 、马齿苋 (Portulaca oleracea)、树头菜(Crateva unilocularis)等, 促进了植物的自然更新。适量采摘果实可促进植物 的生长, 野果类蔬菜包括水茄(Solanum torvum)、余 甘子(Phyllanthus emblica)和黄泡(Rubus pectinellus)。 低族的食花文化利用的植物包括白花洋紫荆 (Bauhinia variegata var. candida)、密蒙花(Buddleja officinalis)、矮萱草(Hemerocallis nana) 和木蝴蝶 (Oroxylum indicum), 适量采摘花朵有利于植物生长。

仾族的日常饮食也包括药食同源的保健文化, 不仅为日常生活提供所需营养, 更有各种预防或治 病养生的功效。例如低族利用水芹的嫩茎、叶柄、 花茎部位作为野菜食用, 利用其全草治疗感冒发热, 也具有降低血压的保健用途。低族日常喜欢食用水 偋的嫩茎叶, 并利用其茎叶入药治疗胎毒, 消除痰 积。密蒙花(当地称作染饭花)的花序和花蕾具有清 肝明目、消炎去火的功效, 同时也是野生的天然食 品染料植物, 用来制作黄米饭。仾族人认为食用这 种花染过的饭, 象征着吉祥、喜庆, 祈盼在新的一 年人畜兴旺、五谷丰登, 因此密蒙花在仾族地区还 具有宗教祭祀的文化价值。

\section{2 低族利用药用植物的医药文化}

仾族医药的起源是低族先民在狩猎、采集等生 产和生活实践积累的经验中逐渐形成对动植物、矿 物等资源的药用价值的认识。低族聚居地动植物资 源丰富, 为俪族人民发展医药文化提供了基础, 已 知的药用植物有 1,000 余种, 属于国家重点普查的 药用植物 302 种, 㑑族常用药物有 500 多种, 常用的 民间草药有糖胶树(Alstonia scholaris)、七叶一枝花 
(Paris polyphylla)、龙胆草(Gentiana rigescens)、臭 灵丹 (Laggera pterodonta) 、通光散 (Marsdenia tenacissima)、木蝴蝶等(邓泽和侯凤飞, 2014)。仾族 生活聚居地常见的七叶一枝花, 佤名Mgah gon ai (嘎关艾), 被低族奉为圣药, 用药已经有 300 多年历 史, 药用部位是根状茎, 清热解毒、消炎止痛、止 血。主治胃痛、痛疮肿毒、跌打损伤、骨折、风湿 性关节炎、刀伤、蛇咬伤。

仾族常用的植物药材一般随用随采, 或采集晒 干备用。仾族民间医生在配伍用药时, 有 $60 \%$ 的药 都会放入引药。这些引药多具有芳香理气、舒筋活 血镇痛作用, 如草果、胡椒、丁香、生姜、白酒、 米酒、红糖、冰糖、蜂蜜等。由于历史上交通闭塞, 医药和医学知识传入较少, 低族在长期的社会生活 实践中形成了独特的用药经验和医药处方。低族信 奉 “万物有灵” 的原始宗教, 重视人与自然的和谐相 处。俩族医药受此影响, 认为自然界中所有的动物、 植物和矿物等都是药物, 是 “巫医一体”的统一体。 仾族草医结合本民族生活地区的药材资源特殊性, 创造出上百种医药方剂, 多以单方治疗为主, 对俪 族人民的健康和繁衍发展发挥了重要作用。

\section{3 仾族利用染料植物的织锦服饰文化}

织锦文化是㑑族传统服饰文化的重要组成部 分。纺线原料最初是采集野生的木棉树 (Bombax ceiba) 的种毛制作棉布, 随后㑑族地区开始普遍种 植棉花, 棉花成为了主要的纺织材料。佤族历史上 织锦染料主要使用红、黄、蓝、黑、灰褐五种颜色。 根据关键人物访谈提供的信息, 共 10 科 12 属 13 种野 生植物(表1)。侅族对织锦染料的认识来源于周围环 境的动植物资源, 红色用虫胶(紫梗)染料, 加上酸 性植物汁液; 黄色用黄花煮水作染料; 蓝色用蓝靛 草作染料; 用染好的蓝布或蓝线置于麻栗树皮水内 浸洗成黑色; 灰褐色用麻栗树皮謷水而成。织布前 也会使用小红米染线, 先将小红米煮后蒸熟, 趁热 将织布的线放入其中约10分钟后将线取出晾干, 线 不易断, 织出来的布更结实。可见, 俪族传统织锦 以植物为原料充分表现了因地制宜的特点, 并且是 仾族对当地丰富的植物资源的多用途利用的传统 知识和传统文化的重要体现。

织锦㑑语称作 “待”, 纺织工具采用竹木制作的 腰机, 经过捻线、搓线、绕线、排线、挑花、织布 等工序, 主要用于制作服饰、挎包、被套等。低族
织锦表现的色彩和图案多为山水、森林、花草、雀 鸟等自然元素, 融合了万物有灵的自然崇拜宗教理 念, 涵盖了俪族传统文化的精髓, 在现代已经成为 了低族重要的民族文化标识。

\section{4 仾族利用植物的传统建筑}

仾族的聚居区为山地, 村落顺山势而建, 一般 分布在山顶或山坡平缓地带。因该地区的气候具有 温热、多雨、潮湿的特点, 㑑族的传统房屋是典型 的干栏式建筑, 空气流通、干爽凉快, 可以防潮、 防瘴气。房屋的建筑材料来源于自然环境, 常用的 有8种植物, 如巨龙竹(Dendrocalamus sinicus)、刺栲 (Castanopsis hystrix)、红椿(Toona ciliata)、水冬瓜 树(Alnus cremastogyne)、旱冬瓜(Alnus nepalensis)、 黄杞 (Engelhardtia roxburghiana)、柚木 (Tectona grandis)和木荷(Schima superba)。俪族习惯用茅草 (Themeda triandra)编织草席用作茅草屋房顶。因此, 低族人民习惯在房屋或村寨周围栽培巨龙竹, 用于 建筑或日常生活器血的制作取材, 主要包括生产生 活使用的汤勺、竹杯、竹筒、盐巴筒、䉝饭盒、竹 桌、竹登等。仾族习惯在农历 9 月砍伐竹子不容易 虫蛙, 修建的房子更加牢固。房屋的建造与选址结 合亚热带气候和山地地形, 体现出恆族人民对自然 环境的适应, 利用本地丰富的树种, 形成仾族聚落 特色的茅草屋建筑文化。

\section{2 仾族传统文化对生物多样性保护的作用}

\section{1 自然崇拜对生物多样性的保护}

宗教崇拜对野生动植物形成了有效的保护, 尤 其是自然崇拜的宗教习俗决定了㑑族对居住地周 围自然环境的保护和生物多样性可持续利用的态 度和利用方式(刘德望, 1996; 刘爱忠等, 2000)。俪 族原始的自然崇拜信仰体现了万物有灵, 人与自然 和谐的生态文化观念。自然崇拜的主要形式包括山 水崇拜、动物崇拜、树木崇拜。万物有灵的观念认 为自然界一切生长和活动现象都有灵魂, 比如神 林、神树不能乱砍滥伐, 否则会遭到树魂的惩罚。 低族的动物崇拜也体现了对野生动物保护有利的 观念。他们认为小雀鸟鸣叫的方位可以预测凶吉祸 福, 㑑族的动物崇拜展示了原始宗教文化的一个方 面, 促进了人们对野生动物的主动保护。

在低族社会里反映在原始宗教意识中的风俗 习惯表现为宗教禁忌。低族的神山、神林不允许随 
表1 俪族织锦服饰利用的染料植物

Table 1 Dyeing plants traditionally used by Wa people for brocade clothing

\begin{tabular}{|c|c|c|c|}
\hline 学名 Scientific name & 科名 Family & 利用部位 Used parts & 用途 Usage \\
\hline 密蒙花 Buddleja officinalis & 马钱科 Loganiaceae & 花 Flower & 黄色染料、食用 Yellow dyeing and edible \\
\hline $\begin{array}{l}\text { 白背枫 Buddleja asiatica } \\
\text { 树头菜 Crateva unilocularis }\end{array}$ & $\begin{array}{l}\text { 玄参科 Scrophulariaceae } \\
\text { 山柑科 Capparaceae }\end{array}$ & $\begin{array}{l}\text { 花、叶、根 Flower, leaf and root } \\
\text { 果皮、嫩叶和茎梢 } \\
\text { Peel, tender leaf and shoots }\end{array}$ & $\begin{array}{l}\text { 黄色染料、药用 Yellow dyeing and medicinal } \\
\text { 染料、食用 Dyeing and edible }\end{array}$ \\
\hline 金合欢 Acacia farnesiana & 豆科 Fabaceae & 果荚、根 Fruit pods and root & 黑色染料、药用 Black dyeing and medicinal \\
\hline $\begin{array}{l}\text { 板蓝. Strobilanthes cusia } \\
\text { 倒吊笔 Wrightia pubescens }\end{array}$ & $\begin{array}{l}\text { 爵床科 Acanthaceae } \\
\text { 夹竹桃科 Apocynaceae }\end{array}$ & $\begin{array}{l}\text { 叶、根 Leaf and root } \\
\text { 叶 Leaf }\end{array}$ & $\begin{array}{l}\text { 蓝色染料、药用 Blue dyeing and medicinal } \\
\text { 蓝色染料 Blue dyeing }\end{array}$ \\
\hline 穗序木蓝 Indigofera hendecaphylla & 豆科 Fabaceae & 叶 Leaf & 蓝靛染料 Indigo dyeing \\
\hline 麻栋 Quercus acutissima & 壳斗科 Fagaceae & 树皮 Bark & 灰褐色染料 Grayish-brown dye \\
\hline 假柿木姜子 Litsea monopetala & 樟科 Lauraceae & 紫胶虫寄生树 Lac host & 红色紫胶染料 Red lac dyeing \\
\hline 火绳树 Eriolaena spectabilis & 锦葵科 Malvaceae & 紫胶虫寄生树 Lac host & 红色紫胶染料 Red lac dyeing \\
\hline 翅果麻 Kydia calycina & 锦葵科 Malvaceae & 紫胶虫寄生树 Lac host & 红色紫胶染料 Red lac dyeing \\
\hline 山槐 Albizia kalkora & 豆科 Fabaceae & 紫胶虫寄生树 Lac host & 红色紫胶染料 Red lac dyeing \\
\hline 聚果榕 Ficus racemosa & 桑科 Moraceae & $\begin{array}{l}\text { 紫胶虫寄生树、果实 } \\
\text { Lac host and fruit }\end{array}$ & 红色紫胶染料、食用 Red lac dyeing and edible \\
\hline
\end{tabular}

便进入，神林(鬼林)是低族村寨固定的祭祀场所, 乱动神林的一草一木将会受到神灵的惩罚。仾族村 寨有崇拜神树的习俗, 如村寨边的大榕树被认为能 保佑平安、抵挡灾难、压制病魔, 因此在习惯法中 规定不得砍伐, 大榕树在村寨附近受到严格保护。 这种自然崇拜和禁忌反映了㑑族人与自然和谐相 处的生态观念, 不仅有效地减少了自然灾害, 也维 持了生态平衡, 保护了当地生物多样性。

\section{2 习惯法对生物多样性保护的积极作用}

低族习惯法是低族在长期保护、利用、管理自 然资源的过程中形成的一系列行为规范和约束性 管理制度。近代以前, 低族没有自己的文字, 习惯 法口头传承、世代相传, 社会全体成员共同遵循。 低族的习惯法规定了生产生活的方方面面, 包括放 牧、砍树、采猎、环境保护等。习惯法对低族村民 的行为具有约束性。㑑族以“无树不成村, 少林必缺 水” 作为古训告诫子孙保护水源林的必要性, 水源 林的树木禁止砍伐, 违者轻则罚款, 重则逐出村寨, 仾族人对水源地与森林保护的内在联系的深刻认 识促使他们传承了生态保护的优良传统。倫族社会 对神林制定了严格的管理制度, 如任何人不得随意 乱闯神林, 不得砍伐神林树木; 不得砍伐或破坏大 榕树, 盖房子必须要经过头人同意才能砍伐木材。 现今㑑族村寨周围的原始森林保存状况良好, 说明 习惯法的约束力起到了重要作用。可以看出, 恆族
在自然崇拜的基础上形成的习惯法对当地的生物 多样性保护发挥了作用, 通过礼俗禁忌对行为和活 动进行制约, 从文化层面有效地保护了阿恆山区的 自然资源和生态环境。

\section{3 传统节庆对生物多样性的保护}

仾族的传统节庆大多与宗教祭祀和生产实践 活动有关, 包括与农事有关的播种节、新米节、新 火节、新水节、叫谷魂、拉木鼓等节庆活动。这些 节庆与活动需要剽牛、杀猪、杀鸡等祭祀仪式, 并 且需要芭蕉、稻米、茶叶、水酒等食物供奉和祭祀 神灵, 以表达对神灵的敬仰与膜拜。比如祭祀人类 祖先化身 “莫伟”的木鼓节, 祭祀稻神或谷魂的迎新 谷节, 祭祀谷神、水神和雨神的播种节等祭祀活动 需要各种动植物用来作祭祀物品, 特别是牛、鸡、 猪是重要的供品, 在每个村寨都饲养有水牛、黄牛、 鸡等畜禽动物, 也会保留种植小红米、红旱谷等地 方品种作物。在节日中还会交换甘蔗、芭蕉、糯米 粑粑等礼品, 寄托了㑑族人对幸福团圆生活的美好 愿望。传统节庆保护了当地的农业生物资源, 生产 生活习俗促进了㑑族人对自然资源的可持续管理 和利用, 并且栽培、驯化和选育了适宜当地气候环 境和饮食文化需求的传统农业生物资源。

\section{唒族传统文化的保护现状与威胁因素}

低族传统文化随着文化旅游产业的发展和产 
业转型逐步受到重视。以非物质文化遗产为代表, 西盟县目前共有国家级非遗项目 2 项, 省级非遗项 目5项，市级非遗项目71项，县级非遗项目64项。非 物质文化遗产的保护工作不仅培养了一批国家级、 市级、县级的非物质文化遗产传承人, 也建立了传 统文化和传统知识的重要保护机制。如西盟县的俪 族织锦入选第五批国家级非物质文化遗产代表性 项目名录, 逐渐成为恆族手工艺品的代表, 当地成 立了工作室和培训机构, 成为文化扶贫增收的途径 之一, 促进了妇女传承和保护织锦文化和知识。

政策导向、生产生活方式改变和资源锐减等因 素影响了俪族社区与生物资源相关的传统文化和 知识的传承与保护。国家林业与农业政策确定了佤 族地区的林地性质和固定耕地权属, 低族刀耕火种 的传统农业方式已经消失, 也影响了佤族对野生植 物资源的采集和利用, 自给自足的传统农业以及采 集野生资源的生活方式向现代化单一化的农业产 品转型, 当地农业生物资源和相关传统文化的消失 速度加快。㑑族织锦的原料不再依赖传统的织染植 物和织染方法, 在一定程度上保护了当地的野生植 物, 但纺线、染线的原料选择和染料制作技术和知 识逐渐消失。低族地区房屋改造工程已经基本完成, 㑑族人停止砍伐树木和竹林用于建造房屋和器具, 但同时与建新房相关的传统文化与习俗逐渐消失。

㑑族医药主要依赖当地的植物资源, 环境变化和资 源锐减使部分医药植物已经不易采集, 同时现代医 疗技术的引入和正规医院的建立使传统㑑族医药 遭到冲击, 其发展和传承面临考验。

保护意识薄弱也是制约传统文化发展的因素 之一。随着低族地区与外界的信息交流增加, 许多 年轻人认为传统民族文化已经过时, 缺乏文化传承 的意识和对传统文化价值的认知。㑑族文化依靠口 传的方式传承, 但㑑族语言在社区的使用和传授逐 渐减少, 老人相继去世, 年轻人对传统文化的兴趣 降低, 使仾族传统知识出现了传承断代的风险。

市场化的发展导致低族的传统民间技艺受到 不同程度的外来文化侵蚀, 发展空间越来越小,。恆 族社区缺乏将特色生物资源转化为市场商品的能 力, 依托民族文化发展经济的潜力仍需要深入发 掘。以西盟地区的低族织锦为例, 纯手工织布全程 大约需要一周至20天左右, 时间成本高、效率低, 机织方式使手工织锦逐渐被放弃, 而且外来服饰文
化的影响使织锦已经不再是㑑族人民日常服饰, 佤 族织锦产业急需适应现代市场需求和审美的转变。

总体来说, 这些驱动因素的综合影响导致了恆 族地区生物多样性的下降和文化多样性消失的风 险。一味追求经济效益不利于传统文化和生物资源 的保护和传承, 生物多样性是可持续发展的重要物 质保障, 如何保护和传承低族传统文化促进生物多 样性保护, 弘扬佤族积极的生态保护观念和习俗, 是低族社会可持续发展面临的重要问题。

\section{4 小结}

\section{1 恆族文化多样性与生物多样性之间的关系}

仾族文化多样性与生物多样性之间相互影响, 相辅相成。仾族独特的传统文化促进了生物多样性 的可持续利用管理与保护。一方面, 俩族地区丰富 的生物多样性为传统文化的产生和发展提供了物 质基础, 低族人民对当地生物多样性的管理和利用 也形成了多样的传统文化实践和传统知识。俩族采 集和利用当地生物资源用于食用、药用、建筑和服 饰, 充分显示了㑑族文化依托于当地的生物多样性, 是丰富的生物多样性的直接表现。另一方面, 㑑族 的传统文化也促进了对生物资源的持续更新与保 存, 发挥了保护生物多样性的积极作用。

\section{2 少数民族与地方社区生物多样性与文化多样 性保护的建议}

少数民族与地方社区的传统文化是生物多样 性保护的参与者和实践者, 由于文化多样性和生物 多样性面临相同的压力, 应该由国家的自然保护部 门同少数民族与地方社区共同合作，制定针对两者 的综合保护策略(图2)。

(1)从国家法规到地方行动增强保护传统文化 的立法和政策。中国是《生物多样性公约》与《保 护非物质文化遗产公约》的缔约国, 要在在国家层 面制定传统知识保护的法律法规促进生物资源的 可持续利用和传统文化的保护, 需要相关政府机构 和地方社区的协作参与。(2)在社区层面通过传统知 识与文化的整理、记录和传承活动, 形成传统知识 编目和数据库。在此过程中使㑑族人获得文化认同, 开展传统知识、语言等的保护和传承活动和自然资 源的管理实践, 增强文化自信与民族自豪感。例如 认可非遗传承人和传承项目, 通过开发非物质文化 遗产项目增加个人或社区的就业机会和收入。增强 


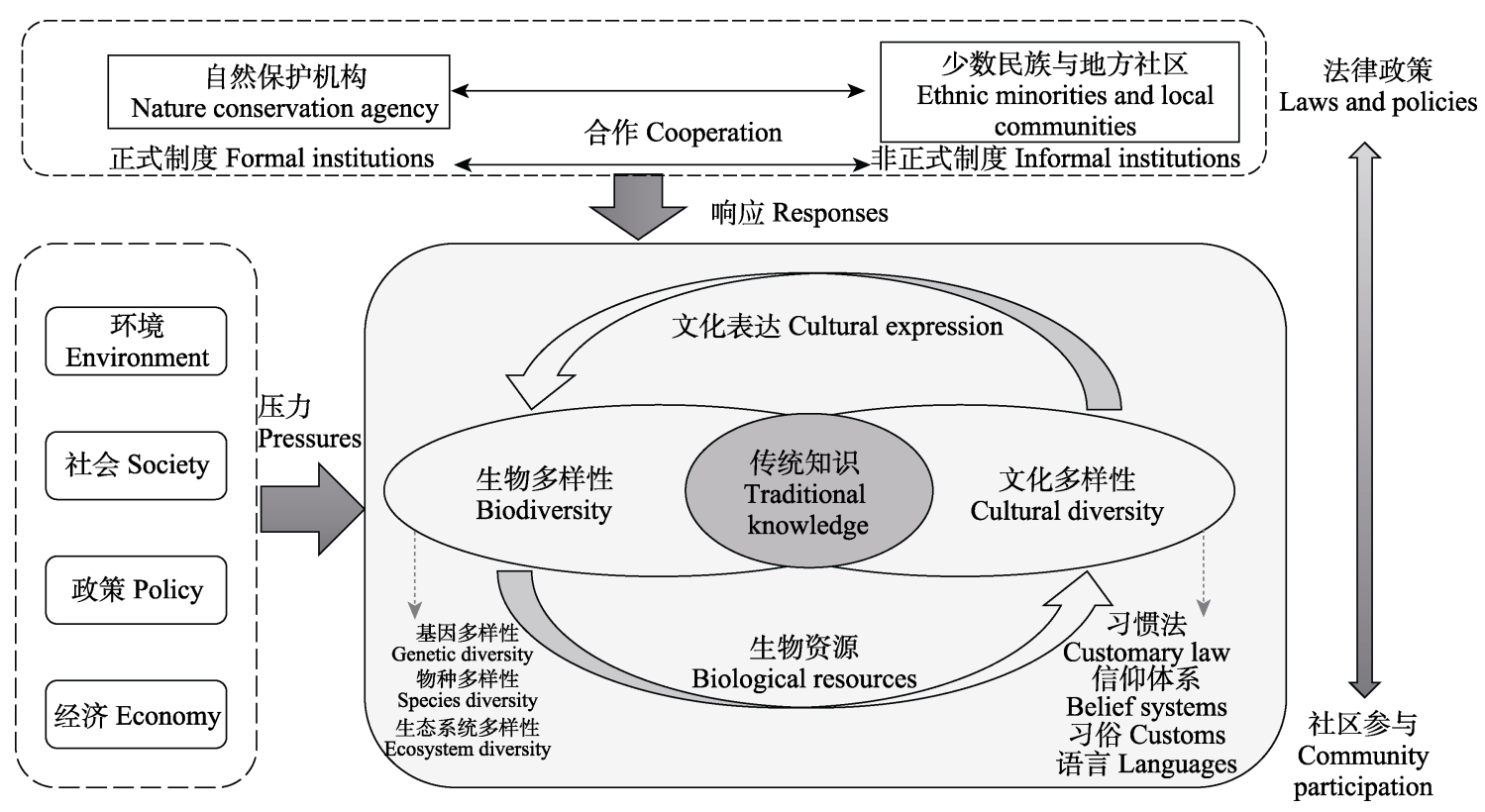

图2 少数民族与地方社区生物多样性与文化多样性的压力与保护策略

Fig. 2 Pressures and protection strategies for biodiversity and cultural diversity in ethnic minority and local communities

传统知识的代际传递，提高年轻一代对本民族传统 知识和文化保护的积极性和主动性, 形成保护和传 承的良性发展局面。(3)从公众宣传和科学研究方面 增强对传统文化的认识和开发利用。积极向公众宣 传少数民族优秀的传统文化, 开设传统知识教育课 程, 建立传统文化培训基地, 开发相关的实践课程 和主题活动, 使公众认识到传统文化对生物多样性 保护的重大贡献。同时, 培养高素质的传统知识保 护专业队伍, 加强跨学科研究, 尤其是在民族生态 学和民族植物学方向发掘传统知识的应用领域, 在 民族文化保护生物多样性的实践中, 以地方特色生 物资源和民族文化为产业推动社区可持续发展。

\section{ORCID}

邵桦 (1D) https://orcid.org/0000-0002-5171-1545

杨京彪 (iD) https://orcid.org/0000-0003-2476-0381

薛达元 (1) https://orcid.org/0000-0001-5399-6938

\section{参考文献}

Cao N, Xue DY (2019) On biodiversity conservation by Zhuang traditional culture: A case study in Jingxi City of Guangxi Zhuang Autonomous Region. Biodiversity Science, 27, 728-734. (in Chinese with English abstract) [曹宁, 薛 达元 (2019) 论壮族传统文化对生物多样性的保护: 以 广西靖西市为例. 生物多样性, 27, 728-734.]

Cocks ML, Wiersum F (2014) Reappraising the concept of biocultural diversity: A perspective from South Africa.
Human Ecology, 42, 727-737.

Dao ZL, Long CL, Liu YT (2003) On traditional use of plants by the Nu people community of the Gaoligong Mountains, Yunnan Province. Biodiversity Science, 11, 232139. (in Chinese with English abstract) [刀志灵, 龙春林, 刘怡涛 (2003) 云南高黎贡山怒族对植物传统利用的初步研究. 生物多样性, 11, 231-239.]

Deng Z, Hou FF (2014) Wa Medicine. Publishing House of Ancient Chinese Medicine Books, Beijing. (in Chinese) [邓 泽, 侯风飞 (2014) 低族医药. 中医古籍出版社, 北京.]

Ens EJ, Pert P, Clarke PA, Budden M, Clubb L, Doran B, Douras C, Gaikwad J, Gott B, Leonard S, Locke J, Packer J, Turpin G, Wason S (2015) Indigenous biocultural knowledge in ecosystem science and management: Review and insight from Australia. Biological Conservation, 181, 133-149.

Feng JM, He HM, Zhu YY, Li CY (2010) Correlation between geographic patterns of cultivar diversity of rice (Oryza sativa L.) and environmental factors, local culture in Yunnan. Journal of Yunnan Agricultural University (Natural Science), 25, 451457. (in Chinese with English abstract) [冯建孟, 何汉明, 朱有勇, 李成云 (2010) 云南地区稻作 品种多样性的地理分布格局及其与自然环境和民族文化 的关系. 云南农业大学学报(自然科学版), 25, 451-457.]

Frainer A, Mustonen T, Hugu S, Andreeva T, Arttijeff EM, Arttijeff IS, Brizoela F, Coelho-De-souza G, Printes RB, Prokhorova E, Sambou S, Scherer A, Shadrin V, Pecl G (2020) Opinion: Cultural and linguistic diversities are underappreciated pillars of biodiversity. Proceedings of the National Academy of Sciences, USA, 117, 26539-26543.

Hill R, Cullen-Unsworth LC, Talbot LD, Mcintyre-Tamwoy S 
(2011) Empowering Indigenous peoples' biocultural diversity through World Heritage cultural landscapes: A case study from the Australian humid tropical forests. International Journal of Heritage Studies, 17, 571-591.

Liu AZ, Pei SJ, Chen SY (2000) An investigation and study on the plant worship by Yi people in Chuxiong, Yunnan. Chinese Biodiversity, 8, 130-136. (in Chinese with English abstract) [刘爱忠, 裴盛基, 陈三阳 (2000) 云南楚雄彝族 植物崇拜的调查研究. 生物多样性, 8, 130-136.]

Liu DW (1996) Taking religion as an effective way to protect wild animals and plants. Chinese Biodiversity, 4, 123124. (in Chinese) [刘德望 (1996) 引用宗教是保护好野生动植 物的有效途径. 生物多样性, 4, 123-124.]

Loh J, Harmon D (2005) A global index of biocultural diversity. Ecological Indicators, 5, 231-241.

Long CL, Pei SJ (2003) Cultural diversity promotes conservation and application of biological diversity. Acta Botanica Yunnanica, 25(Suppl. 14), 11-22. (in Chinese with English abstract) [龙春林, 裴盛基 (2003) 文化多样性促 进生物多样性的保护和利用. 云南植物研究, 25(增刊14), 11-22.]

Long CL, Zhang FY, Pei SJ, Chen SY (1999) Impacts of traditional culture of $\mathrm{Yi}$ nationality upon biodiversity in Zixishan Mountain area, Yunnan. Chinese Biodiversity, 7, 245-249. (in Chinese with English abstract) [龙春林, 张方 玉, 裴盛基, 陈三阳 (1999) 云南紫溪山彝族传统文化对 生物多样性的影响. 生物多样性, 7, 245-249.]

Luo ZJ (1995) The Wa Social History and Culture. China Minzu University Press, Beijing. (in Chinese) [罗之基 (1995) 低族 社会历史与文化. 中央民族大学出版社, 北京.]

Mao SX, Shen Y, Deng HB (2017) Progress in biocultural diversity research. Acta Ecologica Sinica, 37, 8178186. (in Chinese with English abstract) [毛舒欣, 沈园, 邓红兵 (2017) 生物文化多样性研究进展. 生态学报, 37, 8179-8186.]

Meng JL (2010) Preliminary discussion on Wa ethnic ecological culture of Ximeng and forest resource management. Forest Inventory and Planning, 35(2), 89-92. (in Chinese with English abstract) [孟建林 (2010) 西盟佤 族生态文化与森林资源管理初探. 林业调查规划, 35(2), 89-92.]

Persic A, Martin G (2008) Links Between Biological and Cultural Diversity: Report of an International Workshop. UNESCO, Paris.

Plieninger T, Kohsaka R, Bieling C, Hashimoto S, Kamiyama C, Kizos T, Penker M, Kieninger P, Shaw BJ, Sioen GB, Yoshida Y, Saito O (2018) Fostering biocultural diversity in landscapes through place-based food networks: A "solution scan” of European and Japanese models. Sustainability Science, 13, 219-233.

Pradhan A, Ormsby AA (2020) Biocultural conservation in the sacred forests of Odisha, India. Environmental Conservation, 47, 190-196.

Pretty J, Adams B, Berkes F, de Athayde SF, Dudley N, Hunn E, Maffi L, Milton K, Rapport D, Robbins P, Sterling E, Stolton S, Tsing A, Vintinnerk E, Pilgrim S (2009) The intersections of biological diversity and cultural diversity: Towards integration. Conservation and Society, 7, 100-112.

Shao H, Xue DY (2017) Influence of traditional Wa culture on vegetable germplasm diversity in Yunnan Province. Biodiversity Science, 25, 46-52. (in Chinese with English abstract) [邵桦, 薛达元 (2017) 云南㑑族传统文化对蔬 菜种质多样性的影响. 生物多样性, 25, 46-52.]

Singh RK, Pretty J, Pilgrim S (2010) Traditional knowledge and biocultural diversity: Learning from tribal communities for sustainable development in northeast India. Journal of Environmental Planning and Management, 53, 511-533.

Wang YJ, Wang YL, Jiao AX, Cai J, Yang JB, Ruan RC, Xue DY (2015) Influence of national traditional culture on crop genetic diversity-Take an example of Kam Sweet Rice in Liping County of Guizhou Province. Journal of Natural Resources, 30, 617-628. (in Chinese with English abstract) [王艳杰, 王艳丽, 焦爱霞, 才吉卓玛, 杨京彪, 阮仁超, 薛达元 (2015) 民族传统文化对农作物遗传多样性的影 响——贵州黎平县香禾糯资源为例. 自然资源学报, 30, 617-628.]

$\mathrm{Xu} \mathrm{ZF} \mathrm{(2015)} \mathrm{Conservation} \mathrm{of} \mathrm{biodiversity} \mathrm{and} \mathrm{cultural}$ diversity are two sides of a coin: Xishuangbanna Dai's ecological culture as an example. Biodiversity Science, 23, 126-130. (in Chinese with English abstract) [许再富 (2015) 生物多样性保护与文化多样性保护是一枚硬币的两面: 以西双版纳傣族生态文化为例. 生物多样性, 23, 126-130.]

Xue DY, Guo L (2009) On concepts and protection of traditional knowledge. Biodiversity Science, 17, 135-142. (in Chinese with English abstract) [薛达元, 郭泺 (2009) 论传统知识的概念与保护. 生物多样性, 17, 135-142.]

Yang LX, Pei SJ, Zhang Y (2019) Action research on Tibetan sacred nature sites (SNS) conservation in Tibetan community in NW Yunnan. Biodiversity Science, 27, 749-757. (in Chinese with English abstract) [杨立新, 裴盛 基, 张宇 (2019) 滇西北藏区自然圣境与传统文化驱动 下的生物多样性保护. 生物多样性, 27, 749-757.]

(责任编委: 龙春林 责任编辑: 时意专)

\section{附录 Supplementary Material}

\section{附录1 俪族社区生物多样性相关的传统知识半结构访谈提纲}

Appendix 1 The Semi-structured interview guideline of traditional knowledge related to biodiversity in Wa community https://www.biodiversity-science.net/fileup/PDF/2020480-1.pdf 
邵桦, 杨京彪, 薛达元 (2021) 低族传统文化在生物多样性保护中的作用. 生物多样性, 29, 1120-1127.

http://www.biodiversity-science.net/CN/10.17520/biods.2020480

\section{附录 1 仾族社区生物多样性相关的传统知识半结构访谈提纲}

Appendix 1 The Semi-structured interview guideline of traditional knowledge related to biodiversity in Wa community

背景信息:

地点: 县 镇 村

姓名: 性别:

民族：

年龄: $\square 60$ 岁以上 $\square$ 40-59岁 $\square 20-39$ 岁 $\square 20$ 岁以下

受教育程度: $\square$ 不识字 $\square$ 小学 $\square$ 初中 $\square$ 高中 $\square$ 大学以上

家庭人均年收入: $\square<5000$ 元 $\square 5000-10000$ 元 $\square$ 10000-20000元 $\square>20000$ 元

1. 日常栽培种植的农作物（粮食作物、经济作物等）有哪些? 有哪些是仍然保存并种植利 用的地方品种?

2. 俪族日常采集的野生植物有哪些种?
a) 有哪些食用类的野生植物？其利用部位和食用方式如何？
b) 有哪些医用类的野生植物？有哪些医药用途和方剂？
c) 有哪些是作为织锦的传统织染方法和利用的植物？传统纺织工艺如何？
d) 有哪些为传统建筑（茅草房）利用的建材植物？传统建筑方法与习俗有哪些?
e) 有哪些植物具有文化象征意义?
f) 还有哪些其他用途的植物?

3. 恆族的自然崇拜体现在哪些方面? 低族对野生动植物利用的禁忌和习俗有哪些?

4. 低族有哪些需要遵守的保护动植物的习惯法?

5. 俪族的传统节日有哪些? 哪些文化和习俗促进了植物资源的利用和保护?

6. 您对传统文化生物多样性之间的关系有什么看法? 低族传统文化如何发挥生物多样性 保护的作用?

7. 传统文化的变迁趋势如何? 有哪些因素影响其变化进程?

8. 现今有哪些措施对低族传统文化的保护和传承有积极作用?

9. 您认为还有哪些措施能促进传统文化的保护与传承? 